\title{
WHAT DOES SUSTAINABLE CONSUMPTION REALLY MEAN? A THREE-DIMENSIONAL MEASUREMENT APPROACH
}

\author{
Barbara Seegebarth, Technische Universität Braunschweig, Germany \\ Mathias Peyer, Universität Potsdam, Germany \\ Anja Buerke, HHL Leipzig Graduate School of Management, Germany \\ Ingo Balderjahn, Universität Potsdam, Germany \\ Manfred Kirchgeorg, HHL Leipzig Graduate School of Management, Germany \\ Klaus-Peter Wiedmann, Leibniz University of Hannover, Germany
}

\begin{abstract}
The importance of understanding consumers' perceptions of sustainable consumption is increasingly recognized in marketing and consumer research (Prothero et al. 2011). Sustainable consumption patterns have been extensively investigated over several decades by behavioral and social scientists (a review is given by Burgess et al. 2003). Even though the understanding of sustainability is commonly grounded on the triple bottom line approach (Elkington 1997), a one-dimensional operationalization has often been applied in previous empirical research (Bohlen, Schlegelmilch, and Diamantopoulos 1993).

While individual scales to measure the environmental (e.g., Kaiser, Wölfing, and Fuhrer 1999), social (e.g., Sen and Bhattacharya 2001), and economic (e.g., Cowles and Crosby 1986) dimensions of sustainable consumption exist, combined measurements are rare. Thus, the main objective of this study was the development of a scale to measure consumers' consciousness for environmentally friendly, socially just and economically frugal consumption (CSC).

Consciousness was operationalized by combining individual's belief with the importance consumers attach to these dimensions (Cohen, Fishbein, and Ahtola 1972). This scale was administered to 378 graduate and undergraduate students from three German universities in summer 2012. Participants were male (44.8\%) and female students from different subjects with a mean age of 23.9 years.

Results indicate an appropriate psychometric quality of the CSC scale and provide support for CSC three-dimensional composite score. Suggestions for future research and validation steps are presented to unleash the considerable potential of the newly developed CSC scale in the study of sustainable consumption.
\end{abstract}

References available upon request 